\title{
Author Correction: Estimating carbon storage in urban forests of New York City
}

\author{
Clara C. Pregitzer $^{1,2} \cdot$ Chloe Hanna $^{1} \cdot$ Sarah Charlop-Powers ${ }^{1} \cdot$ Mark A. Bradford $^{2}$ \\ Published online: 22 December 2021 \\ ○) Springer Science+Business Media, LLC, part of Springer Nature 2021
}

\section{Author Correction: Urban Ecosystems \\ https://doi.org/10.1007/s11252-021-01173-9}

The original version of this article unfortunately contains two similar but different estimates. The correct estimate is 1.86 (95\% CI, 1.60 and 2.13) rather than $1.84 \mathrm{C}(95 \% \mathrm{CI}$, 1.58 and 2.10$)$.

The original article has been corrected.

The online version of theoriginal article can be found at https:// doi.org/10.1007/s11252-021-01173-9.

$\triangle$ Clara C. Pregitzer

clara.pregitzer@naturalareasnyc.org

1 Natural Areas Conservancy, 1234 5th Avenue, New York, NY, USA

2 The Forest School, Yale School of the Environment, 195 Prospect St, New Haven, CT 06517, USA 